\title{
The Effect of Displacement Damage on Deuterium Retention in Tungsten Exposed to D Neutrals and $D_{2}$ Gas
}

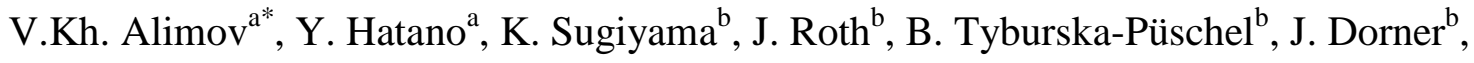 \\ J. Shi ${ }^{\mathrm{a}}$, M. Matsuyama ${ }^{\mathrm{a}}$, K. Isobe ${ }^{\mathrm{c}}$, T. Yamanishi ${ }^{\mathrm{c}}$ \\ ${ }^{a}$ Hydrogen Isotope Research Center, University of Toyama, Toyama 930-8555, Japan \\ ${ }^{\mathrm{b}}$ Max-Planck-Institut für Plasmaphysik, EURATOM Association, D-85748 Garching, Germany \\ ${ }^{\mathrm{c}}$ Tritium Technology Group, Japan Atomic Energy Agency, Tokai, Ibaraki 319-1195, Japan
}

\begin{abstract}
Samples of polycrystalline ITER-grade $\mathrm{W}$ and recrystallized $\mathrm{W}$ were irradiated at room temperature with $20 \mathrm{MeV} \mathrm{W}$ ions to displacement damage up to $0.5 \mathrm{dpa}$. The damaged $\mathrm{W}$ samples were then exposed to (i) D neutrals at 403-573 K and (ii) D2 gas at 673-1073 K and pressures of 1.2 and $100 \mathrm{kPa}$. Trapping of deuterium in the damage zone was examined by the $\mathrm{D}\left({ }^{3} \mathrm{He}, \mathrm{p}\right){ }^{4} \mathrm{He}$ nuclear reaction with ${ }^{3} \mathrm{He}$ energies between 0.69 and $4.0 \mathrm{MeV}$ allowing determination of the $\mathrm{D}$ concentration up to a depth of $6 \mathrm{~lm}$. It has been found that generation of the $\mathrm{W}$-ion-induced displacement damage leads to accumulation of deuterium in the damage zone up to concentration depending on the exposure temperature and, at temperatures $\geq 673$ $\mathrm{K}$, on the $\mathrm{D}_{2}$ gas pressure. Thermal desorption spectra allowed a conclusion that deuterium is mainly accumulated in the form of $\mathrm{D}$ atoms bound to inner walls of vacancy clusters.
\end{abstract}

PACS: 52.40.Hf, 61.72.Qq, 61.80.Jh

PSI-20 Keywords: Deuterium inventory, Tungsten

*Corresponding author address: Hydrogen Isotope Research Center, University of Toyama, 3190 Gofuku, Toyama-shi, Toyama 930-8555, Japan

*Corresponding author e-mail: vkahome@mail.ru

Presenting author: Vladimir Alimov

Presenting author e-mail: vkahome@mail.ru 


\section{Introduction}

As a material for plasma-facing components in future fusion reactors, tungsten (W) will be subjected to intensive fluxes of energetic deuterium (D) and tritium (T) as well as $14 \mathrm{MeV}$ neutrons (n). Neutron irradiation generates displacements in the bulk of $\mathrm{W}$ and creates thus defects at which hydrogen isotopes can be trapped [1,2]. These processes lead to concerns about tritium inventory in the n-irradiated $\mathrm{W}$ after long-term deuterium-tritium plasma exposure. One of the ways to investigate the influence of n-produced defects on the hydrogen isotope inventory is to simulate displacement damage in tungsten using irradiation with energetic ions. Radiation damage generated by fusion neutrons and by $\mathrm{MeV} \mathrm{W}$ ions is to some extent comparable [3]. For both neutrons and heavy ions, the energy distribution of primary knock-on atoms peaks at high energies, and they both create dense collision cascades [4]. However, damage created by heavy ions is concentrated in a narrow region below the surface, while neutron-induced damage extends to larger depths.

It has been shown that defects produced by irradiation with light $(\mathrm{H}, \mathrm{Si})$ and heavy $(\mathrm{W})$ ions enhance deuterium retention in $\mathrm{W}$ materials after subsequent irradiation with $\mathrm{D}$ ions or exposure to D and D-He plasmas [5-13]. However, exposure to high flux plasmas interferes with the modification of the near-surface by heavy-ion-induced defects. If such modification takes place, the effects of displacement damage on the bulk retention of diffusing D atoms cannot be simulated properly by D plasma exposures. The objective of this work is to study $\mathrm{D}$ retention at displacement damage in $\mathrm{W}$ after exposure to low-flux beam of $\mathrm{D}$ neutrals and $\mathrm{D}_{2}$ gas at temperatures up to $1073 \mathrm{~K}$.

\section{Experimental}

Two types of tungsten with a purity of 99.99 wt.\% were used in this work: (i) a polycrystalline ITER-grade tungsten and (ii) the polycrystalline W fully recrystallized at 2073 $\mathrm{K}$ for $1 \mathrm{~h}$ after cutting and polishing.

The ITER-grade $\mathrm{W}$ is deformed (rolled, swaged and/or forged) followed by appropriate heat-treatments to obtain better mechanical properties after the sintering process [14]. The microstructure of the Japanese ITER-grade W produced by A.L.M.T. Corp., Japan, consists of grains elongated along the deformation axis. The grain size is $1-3 \mu \mathrm{m}$ in section and up to 5 $\mu \mathrm{m}$ in length. Individual elongated cracks observed between grains are due to the deformation treatment [15] Square-shaped samples, $10 \times 10 \times 2 \mathrm{~mm}$ in size, were prepared by the manufacturer such that the plasma-facing surfaces were perpendicular to the deformation axis. 
The samples were mechanically polished, cleaned in an acetone ultrasonic bath, and then annealed in vacuum at $1473 \mathrm{~K}$ for $30 \mathrm{~min}$ for stress relief.

Recrystallized W samples were prepared from powder-metallurgy W by A.L.M.T. Corp., Japan. After hot-rolling samples of $10 \times 10 \times 2 \mathrm{~mm}$ in size were cut and followed by dry-hydrogen annealing at $2073 \mathrm{~K}$ for $1 \mathrm{~h}$. In consequence of this, the $\mathrm{W}$ grain size is 20-200 $\mu \mathrm{m}$.

In an implantation chamber connected to the $3 \mathrm{MV}$ tandem accelerator at IPP, Garching, the $\mathrm{W}$ samples were irradiated with $20 \mathrm{MeV} \mathrm{W}$ ions to a fluence of $8 \times 10^{17} \mathrm{~W} / \mathrm{m}^{2}$ at room temperature. As a result, the near-surface layer of the samples was damaged to 0.5 displacements per atom (dpa) at the damage peak situated at a depth of $1.35 \mu \mathrm{m}$. The damage profile was calculated using the program SRIM 2008.03 [16] with a displacement threshold energy of $E_{\mathrm{d}}=90 \mathrm{eV}$ [17].

The damaged $\mathrm{W}$ samples as well as undamaged ones were exposed to D particles at elevated temperatures in the range from 473 to $693 \mathrm{~K}$ in DC glow discharge. The sample on a holder equipped with an ohmic heater and a thermocouple served as anode, whereas a tungsten disc located at a distance of about $10 \mathrm{~cm}$ from the sample holder was used as a cathode. Deuterium pressure in the chamber was maintained at $1 \mathrm{~Pa}, \mathrm{DC}$ discharge voltage was around $400 \mathrm{~V}$, and discharge current averaged about $0.18 \mathrm{~A}$. As a result, the $\mathrm{W}$ sample placed on the sample holder was exposed to uncharged D particles (neutrals) and negatively charged deuterium ions originated in the glow discharge and also to D atoms reflected from the $\mathrm{W}$ cathode. An implantation flux of the D neutrals and negatively charged ions was estimated to be about $2 \times 10^{18} \mathrm{D} / \mathrm{m}^{2} \mathrm{~s}$ with the use of Ti probe exposed in the DC glow discharge at room temperature for 10 and $60 \mathrm{~min}$, while the $\mathrm{D}$ retention in the Ti probe was determined by thermal desorption spectroscopy (TDS). It seems plausible that a fraction of negatively charged D ions in the implantation flux was negligibly small [18], therefore below we can talk about $\mathrm{D}$ neutrals with energies in the range from few $\mathrm{eV}$ (atoms originated in the glow discharge) to $\sim 150 \mathrm{eV}$ (atoms reflected from the cathode [19]).

The undamaged and damaged $\mathrm{W}$ samples were also exposed to $\mathrm{D}_{2}$ gas at pressures of 1.2 and $100 \mathrm{kPa}$ and temperatures in the range from 673 to $1073 \mathrm{~K}$ in a quartz tube connected to the high-vacuum pumping system. The sample was placed inside the quartz tube and heated in a vacuum with the use of an external ohmic heater. The temperature was monitored using a type $\mathrm{K}$ thermocouple contacted directly to the sample inside the tube. As the sample temperature reached the required value, a valve between the tube and the pumping system was 
closed and the tube was filled with $\mathrm{D}_{2}$ gas. The background pressure inside the tube was measured with an ionization gauge, whereas the $\mathrm{D}_{2}$ gas pressure was controlled with a Baratron capacitance manometer. The samples were exposed to $\mathrm{D}_{2}$ gas at $673 \mathrm{~K}$ for $10 \mathrm{~h}$, at 773 and $873 \mathrm{~K}$ for $3 \mathrm{~h}$, at 973 and $1073 \mathrm{~K}$ for $1 \mathrm{~h}$.

The deuterium depth profiles in the $\mathrm{W}$ samples were determined by nuclear reaction analysis (NRA). The $\mathrm{D}\left({ }^{3} \mathrm{He}, \mathrm{p}\right)^{4} \mathrm{He}$ reaction was utilized, and both the $\alpha$ particles and protons were analyzed. The $\alpha$-spectrum was transformed into a $\mathrm{D}$ depth profile at depths up to $\sim 0.5$ $\mu \mathrm{m}$ using the program SIMNRA [20]. To determine the D concentration at larger depths, the energy of the analyzing beam of ${ }^{3} \mathrm{He}$ ions was varied from 0.69 to $4.0 \mathrm{MeV}$. The proton yields measured at twelve different ${ }^{3} \mathrm{He}$ ion energies allow D depth profiles to be measured to depths of up to $6 \mu \mathrm{m}[21,22]$ with acceptable depth resolution [22].

After the NRA measurements, the samples were analyzed ex-situ by thermal desorption spectrometry (TDS). A controlled ohmic heater was used to heat the sample placed inside a quartz tube at a ramp rate of $0.5 \mathrm{~K} / \mathrm{s}$ and the sample temperature was raised to $1300 \mathrm{~K} . \mathrm{H}_{2}$, $\mathrm{HD}$ and $\mathrm{D}_{2}$ molecules released during TDS measurement were monitored by a quadrupole mass spectrometer. It was observed that kinetics of $\mathrm{HD}$ and $\mathrm{D}_{2}$ thermal desorption were different. In most TDS measurements, the HD spectrum was correlated rather with the $\mathrm{H}_{2}$ spectrum. Just to avoid influence of $\mathrm{H}_{2}$ pressure variation on a shape of the deuterium TDS spectrum, we examined $\mathrm{D}_{2}$ signal only. Whereas deuterium was mainly accumulated in the damaged zone at depths of up to $2 \mu \mathrm{m}$ (Figs. 1 and 2), for each TDS experiment the TDS $\mathrm{D}_{2}$ signal integral was intentionally equated to the amount of deuterium determined by NRA.

\section{Results and Discussion}

After exposure of undamaged W samples to D neutrals at temperatures of 403 and $473 \mathrm{~K}$, deuterium is detected in the near-surface layer solely, at depths less than $0.1 \mu \mathrm{m}$ (the depth profiles are not shown).

Generation of displacement damage in the $\mathrm{W}$ materials and subsequent exposure to $\mathrm{D}$ neutrals at temperatures from 403 to $573 \mathrm{~K}$ leads to accumulation of deuterium at depths up to $2 \mu \mathrm{m}$ (i.e., in the damage zone) to a concentration of 0.4-1.1 at.\%, depending on the exposure temperature (Fig. 1). Note that after exposure to $\mathrm{D}_{2}$ gas a pressure of $1 \mathrm{~Pa}$ (the same deuterium pressure was maintained under DC discharge) and temperatures of 403 and $573 \mathrm{~K}$ for $12 \mathrm{~h}$ (i.e., for time period of highest $\mathrm{D}$ neutral fluence), the $\mathrm{D}$ concentration in the damage zone does not exceed $10^{-2}$ at.\%. During $\mathrm{D}$ neutral exposure, the $\mathrm{W}$-ion-induced defects 
become fully occupied to a depth depending on implantation fluence (or time) and are empty at greater depths (Fig. 1b). Thus, the D depth profiles are consistent with saturable strong traps ${ }^{1}$ being filled by $\mathrm{D}$ atoms diffusing from the surface. Accumulation of deuterium in the damage zone is observed also after $\mathrm{D}_{2}$ gas exposure at pressures of 1.2 and $100 \mathrm{kPa}$ and temperatures of 673-1093 K (Fig. 2). It should be noted that in undamaged W exposed to the $\mathrm{D}$ neutrals and $\mathrm{D}_{2}$ gas, the $\mathrm{D}$ concentration at depths $\geq 0.1 \mu \mathrm{m}$ is below the NRA detection limit of $5 \times 10^{-4}$ at. $\%$.

For both $\mathrm{W}$ materials exposed both to $\mathrm{D}$ neutrals and $\mathrm{D}_{2}$ gas at the same conditions, values of the $\mathrm{D}$ concentration (given in $\mathrm{D} / \mathrm{W}$ ) at the depth of the damage peak are comparable (Fig. 3). However, after gas exposure at $673 \mathrm{~K}$ and $100 \mathrm{kPa}$, the D concentration in the ITERgrade $\mathrm{W}$ beyond the damage zone (at depths $\geq 2.5 \mu \mathrm{m}$ ) is noticeably higher than that in the recrystallized W (Fig. 2). Obviously, the intrinsic intergranular cracks inside the ITER-grade $\mathrm{W}$ serve as traps for diffusing $\mathrm{D}$ atoms.

After D loading near room temperature, saturation concentration of D trapped in the damage zone, ${ }^{\text {tr }} C_{\mathrm{D}}$, is about $0.01 \mathrm{D} / \mathrm{W}$ and, as the exposure temperature increases up to $573 \mathrm{~K}$, decreases to about $4 \times 10^{-3} \mathrm{D} / \mathrm{W}$ (Fig. 3). In the case of $\mathrm{D}_{2}$ gas exposure at $\geq 673 \mathrm{~K}$, the concentration ${ }^{\text {tr }} C_{\mathrm{D}}$ depends strongly on the exposure temperature and gas pressure (Fig. 3).

Deuterium atoms injected into damaged $\mathrm{W}$ settle into interstitial solution sites, diffuse through the metal lattice, and become trapped at defects like vacancies and vacancy clusters $[23,24]$ generated from the displacement damage. The results show that the saturation D concentration in the damage zone depends not only on an exposure temperature but also on a concentration of deuterium atoms in solute state [25, 26] (Fig. 3).

TDS spectra of $\mathrm{D}_{2}$ molecules released from the damaged $\mathrm{W}$ materials exposed to $\mathrm{D}$ neutrals at $423 \mathrm{~K}$ demonstrate dominating peak at $930-950 \mathrm{~K}$ and a shoulder at $\sim 820 \mathrm{~K}$. However, after exposure at $573 \mathrm{~K}$, the $\sim 820 \mathrm{~K}$ shoulder disappears and the spectra are characterized by the dominating peak at $950 \mathrm{~K}$ (Fig. 4a). After exposure to $\mathrm{D}_{2}$ gas, the TDS spectra can be described by a single peak at 940-1000 K and high-temperature (1100-1270 K) desorption tail (Fig. 4b).

According to van Veen et al. [26] and modeling deuterium thermal release by Poon et al. [27], a TDS peak at $~ 900 \mathrm{~K}$ can be ascribed to detrapping of atomic deuterium from walls of voids or large vacancy clusters. Formation of large vacancy clusters comprising 300-600

\footnotetext{
${ }^{1}$ Saturable traps are traps having finite capacity. Traps where D in solution becomes trapped when it encounters unoccupied traps are denoted as strong traps [4].
} 
vacancies in $\mathrm{W}$ after irradiation with $50 \mathrm{keV} \mathrm{W}$ ions at $300 \mathrm{~K}$ to damage levels from 0.01 to 5.5 dpa was observed with the use of field ion microscopy [24]. Thus, it is safe to assume that in the $\mathrm{W}$-ion-damaged $\mathrm{W}$, deuterium is mainly accumulated in the form of $\mathrm{D}$ atoms bound to inner walls of large vacancy clusters.

After exposure of damaged $\mathrm{W}$ to low-energy (several tens of eV) D plasmas with high incident ion fluxes $\left(10^{22}-10^{24} \mathrm{D} / \mathrm{m}^{2} \mathrm{~s}\right)$ at temperatures below $600 \mathrm{~K}[9,11-13]$, the $\mathrm{D}$ concentration in the damaged zone is nearly twice as high as that for D neutral exposure with low implanted flux of $\sim 2 \times 10^{18} \mathrm{D} / \mathrm{m}^{2} \mathrm{~s}$ (Fig. 3). This difference can be explained by accumulation of molecular deuterium inside small voids due to high concentration of $\mathrm{D}$ atoms in solution maintained in the near-surface layer under high-flux D plasma exposure. However, under D plasma exposures at temperatures above $650 \mathrm{~K}, \mathrm{D}_{2}$ molecules are released from the voids [26] and D is accumulated mainly as D atoms.

\section{Summary}

In $\mathrm{W}$ materials damaged by irradiation with $20 \mathrm{MeV} \mathrm{W}$ ions at room temperature to 0.5 dpa at the damage peak and subsequently exposed to $\mathrm{D}$ neutrals and $\mathrm{D}_{2}$ gas at elevated temperatures, deuterium accumulates in the damage zone to a saturation concentration depending on the exposure temperature (e.g., $\sim 10^{-2} \mathrm{D} / \mathrm{W}$ at $403 \mathrm{~K}$ and $\sim 4 \times 10^{-5} \mathrm{D} / \mathrm{W}$ at $1073 \mathrm{~K})$ and D concentration in solute state. The high temperature (930-1000 K) single TDS peaks obtained after exposure of the damaged $\mathrm{W}$ materials both to the $\mathrm{D}$ neutrals and $\mathrm{D}_{2}$ gas allow a speculation that deuterium is mainly accumulated in the form of $\mathrm{D}$ atoms bound to inner walls of vacancy clusters.

\section{Acknowledgement}

The authors thank S. Lindig and M. Balden (IPP Garching) for the SEM/FIB analysis of the W materials and M. Fußeder (IPP Garching) for irradiation of the W samples with W ions and technical assistance with the ${ }^{3} \mathrm{He}$ beam analyses. This work was supported by Kakenhi on Priority Areas, 476, Tritium for Fusion, from MEXT, Japan. 


\section{References}

[1] V. Barabash, G. Federici, M. Rödig, et al., J. Nucl. Mater. 283-287 (2000) 138.

[2] H. Iida, V. Khripunov, L. Petrizzi, G. Federici, ITER Nuclear Analysis Report G 73 DDD 2 W 0.2, 2004.

[3] G.S. Was, Fundamentals of Radiation Material Science: Metals and Alloys, Springer, Berlin, Yeidelberg, New York, 2007.

[4] P. Vladimirov, S. Bouffard, C.R. Phys. 9 (2008) 303

[5] M. Fukumoto, H. Kashiwagi, Y. Ohtsuka, et al., J. Nucl. Mater. 390-391 (2009) 572.

[6] W.R. Wampler, R.P. Doerner, Nucl. Fusion 49 (2009) 115023.

[7] W.R. Wampler, R.P. Doerner, Phys. Scripra T138 (2009) 14037.

[8] W.R. Wampler, D.L. Rudakov, J.G. Watkins, C.J. Lasnier, J. Nucl. Mater. 415 (2011) S653.

[9] B. Tyburska, V.Kh. Alimov, O.V. Ogorodnikova, et al., J. Nucl. Mater. 395 (2009) 150.

[10] B. Tyburska, V.Kh. Alimov, O.V. Ogorodnikova, et al., J. Nucl. Mater. 415 (2011) S680.

[11] O.V. Ogorodnikova, B. Tyburska, V.Kh. Alimov, K. Ertl, J. Nucl. Mater. 415 (2011) S661.

[12] V.Kh. Alimov, B. Tyburska-Püschel, Y. Hatano, et al., J. Nucl. Mater. 420 (2012) 370.

[13] M.H.J. 't Hoen, B. Tyburska-Püschel, K. Ertl, et al., Nucl. Fusion 52 (2012) 023008.

[14] T. Hirai, G. Pintsuk, J. Linke, M. Batilliot, J. Nucl. Mater. 390-391 (2009) 751.

[15] V.Kh. Alimov, B. Tyburska-Püschel, S. Lindig, et al., J. Nucl. Mater. 420 (2012) 519.

[16] J.F. Ziegler, SRIM - The stopping and range of ions in matter, ver. SRIM 2008.3, http://srim.org.

[17] Q. Xu, T. Yoshiie, H.C. Huang, Nucl. Instr. and Meth. B 206 (2003) 123.

[18] S.G. Belostotsky, D.V. Lopaev, T.V. Rakhimova, J. Phys.: Conf. Ser. 44 (2006) 162.

[19] W. Eckstein, Rep. IPP 9/117, Max-Planck-Institut für Plasmaphysik, Garching, 1998.

[20] M. Mayer, Rep. IPP 9/113, Max-Planck-Institut für Plasmaphysik, Garching, 1997.

[21] V.Kh. Alimov, M. Mayer, J. Roth, Nucl. Instr. and Meth. B 234 (2005) 169.

[22] M. Mayer, E. Gauthier, K. Sugiyama, U. von Toussaint, Nucl. Instr. and Meth B 267 (2009) 506.

[23] G.H. Kinchin, R.S. Pease, Rep. Prog. Phys. 18 (1955) 1.

[24] A.F. Bobkov, V.T. Zabolotnyi, L.I. Ivanov, et al., Atomic Energy 48(5) (1980) 331.

[25] S.T. Picraux, Nucl. Instr. and Meth. 182-183 (1981) 413. 
[26] Y. Hatano, M. Shimada, V.Kh. Alimov, et al., Trapping of hydrogen isotopes at radiation defects formed in $\mathrm{W}$ by neutron and ion irradiations, J. Nucl. Mater. (submitted to this volume).

[27] A. van Veen, H.A. Filius, J. de Vries, et al., J. Nucl. Mater. 155-157 (1988) 1113.

[28] M. Poon, A.A. Haasz, J.W. Davis, J. Nucl. Mater. 374 (2008) 390. 


\section{Figure captions}

Figure 1. Depth profiles of deuterium retained in damaged ITER-grade W (a) and recrystallized W (b) after exposure to D neutrals. Exposure temperatures and D implantation fluences are indicated in the legends. In both panels, damage depth profiles as calculated by SRIM 2008.03 [16] are also shown.

Figure 2. Depth profiles of deuterium retained in damaged ITER-grade W (a) and recrystallized $\mathrm{W}$ (b) after exposure to $\mathrm{D}_{2}$ gas. Exposure temperatures, gas pressures and exposure durations are indicated in the legends. In both panels, damage depth profiles as calculated by SRIM 2008.03 [16] are also shown.

Figure 3. Saturation concentration of deuterium (D/W) in the damage zone of ITER-grade W and recrystallized $\mathrm{W}$ exposed (i) to $\mathrm{D}$ neutrals and (ii) to $\mathrm{D}_{2}$ gas at pressures of 1.2 and 100 $\mathrm{kPa}$, as a function of exposure temperature. Additionally, D concentrations in the damage zone of W-ion-damaged W materials exposed to low-energy, high-flux D plasmas [9,11-13] are shown for a comparison. The $\mathrm{W}$ materials were damaged by irradiation with $5.5-20 \mathrm{MeV}$ $\mathrm{W}$ ions at room temperature. Types of $\mathrm{W}$ materials and displacement damage levels are indicated in the legends.

Figure 4. Thermal desorption spectra of $\mathrm{D}_{2}$ molecules for damaged ITER-grade $\mathrm{W}$ exposed to $\mathrm{D}$ neutrals (a) and recrystallized $\mathrm{W}$ exposed to $\mathrm{D}_{2}$ gas (b). Exposure temperatures, D implantation fluences, gas pressures and exposure durations are indicated in the legends. The TDS heating rate was $0.5 \mathrm{~K} / \mathrm{s}$. In both panels, the deuterium release rate is shown on a logarithmic scale. 


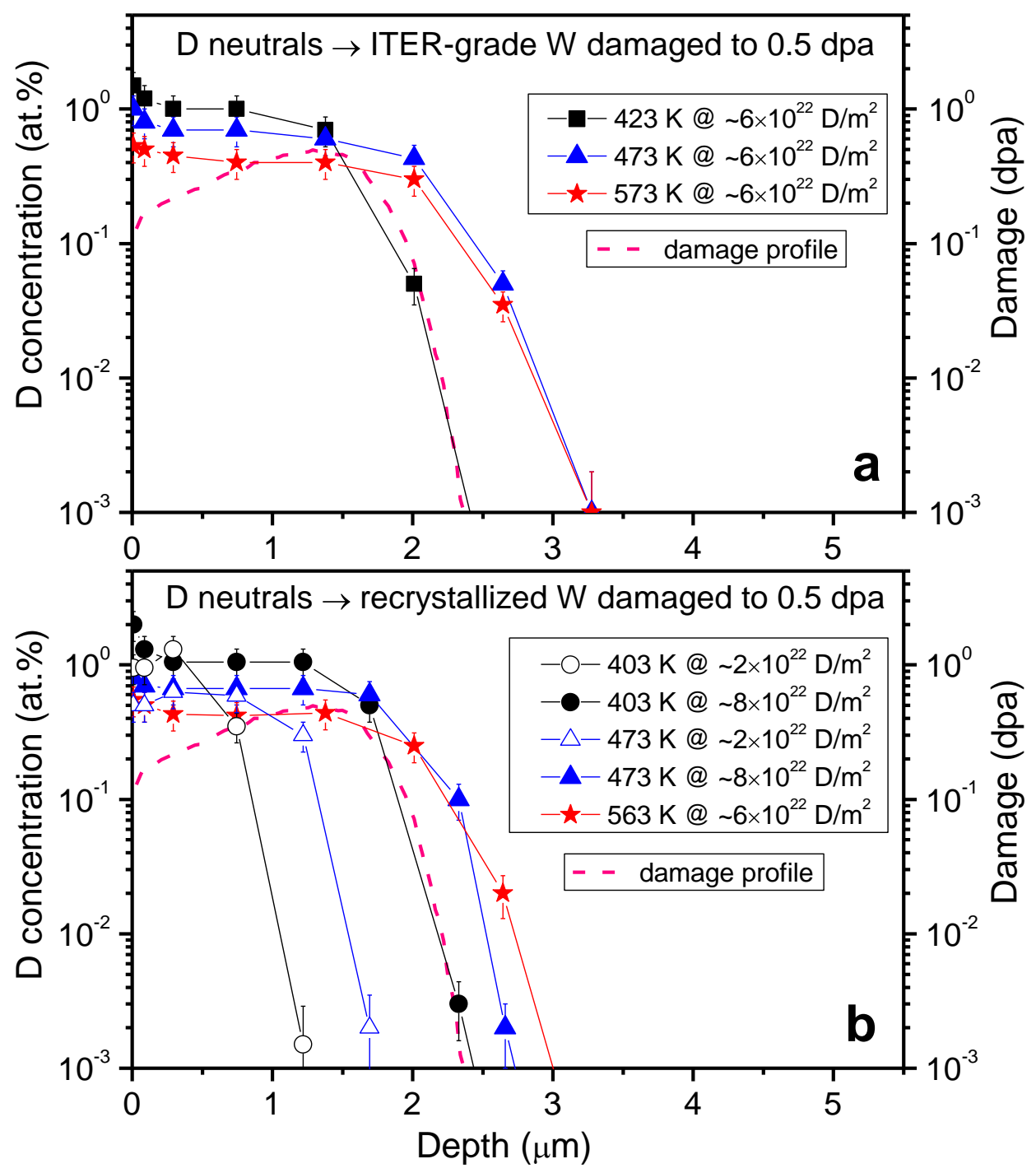

Figure 1. Depth profiles of deuterium retained in damaged ITER-grade W (a) and recrystallized W (b) after exposure to D neutrals. Exposure temperatures and D implantation fluences are indicated in the legends. In both panels, damage depth profiles as calculated by SRIM 2008.03 [16] are also shown. 


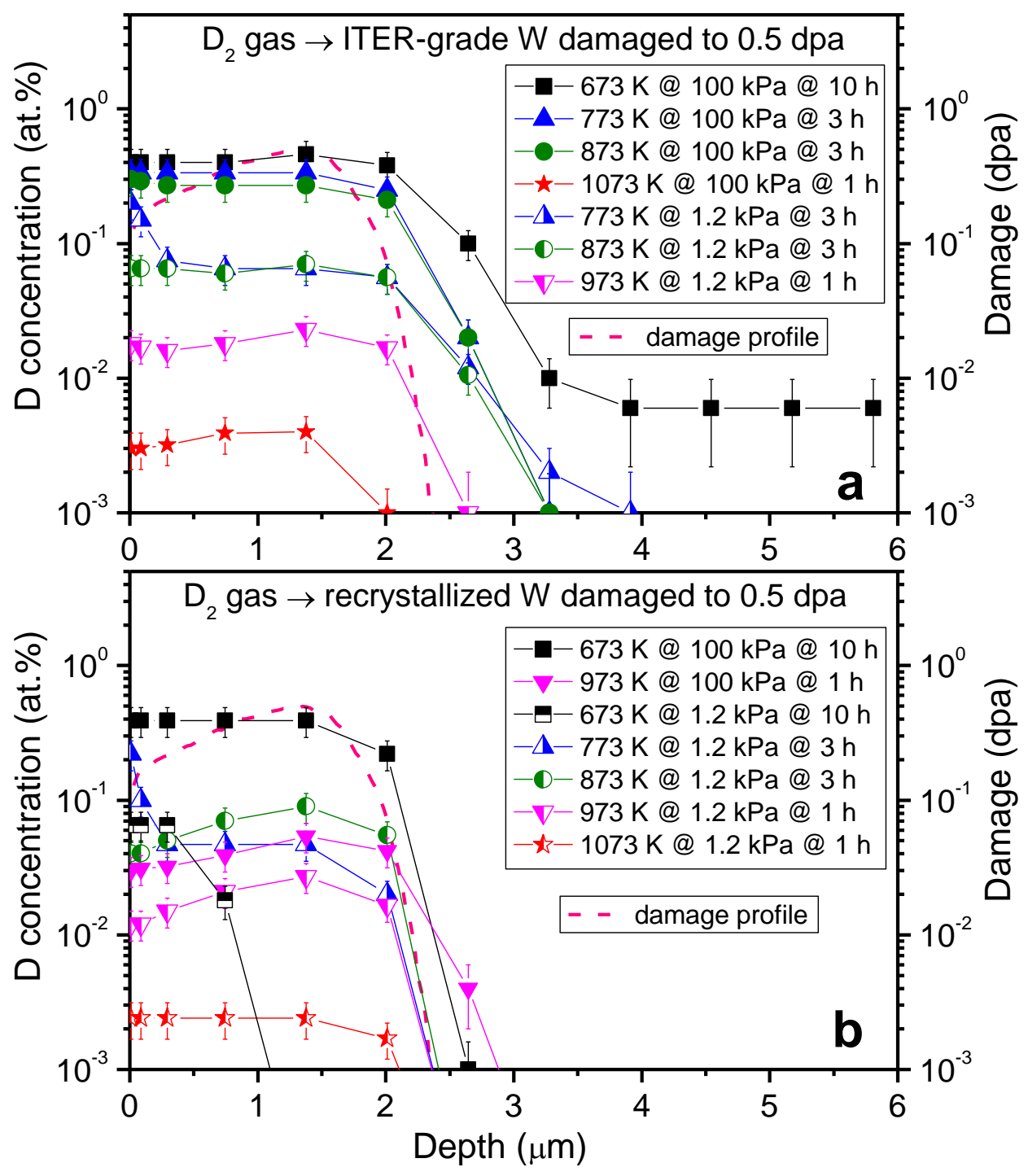

Figure 2. Depth profiles of deuterium retained in damaged ITER-grade W (a) and recrystallized W (b) after exposure to $\mathrm{D}_{2}$ gas. Exposure temperatures, gas pressures and exposure durations are indicated in the legends. In both panels, damage depth profiles as calculated by SRIM 2008.03 [16] are also shown. 


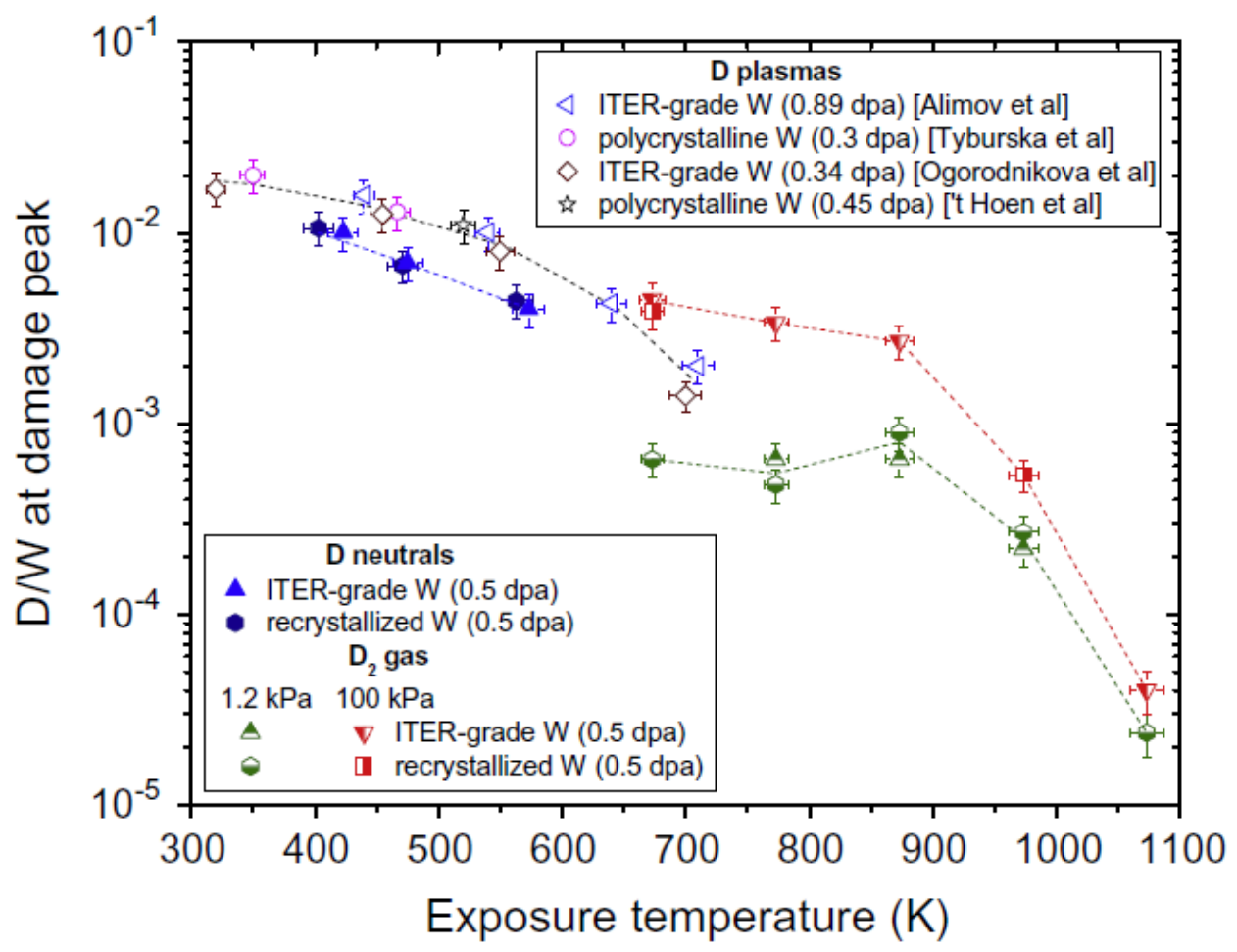

Figure 3. Saturation concentration of deuterium (D/W) in the damage zone of ITER-grade W and recrystallized $\mathrm{W}$ exposed (i) to D neutrals and (ii) to $\mathrm{D}_{2}$ gas at pressures of 1.2 and 100 $\mathrm{kPa}$, as a function of exposure temperature. Additionally, $\mathrm{D}$ concentrations in the damage zone of W-ion-damaged W materials exposed to low-energy, high-flux D plasmas [9,11-13] are shown for a comparison. The $\mathrm{W}$ materials were damaged by irradiation with $5.5-20 \mathrm{MeV}$ $\mathrm{W}$ ions at room temperature. Types of $\mathrm{W}$ materials and displacement damage levels are indicated in the legends. 


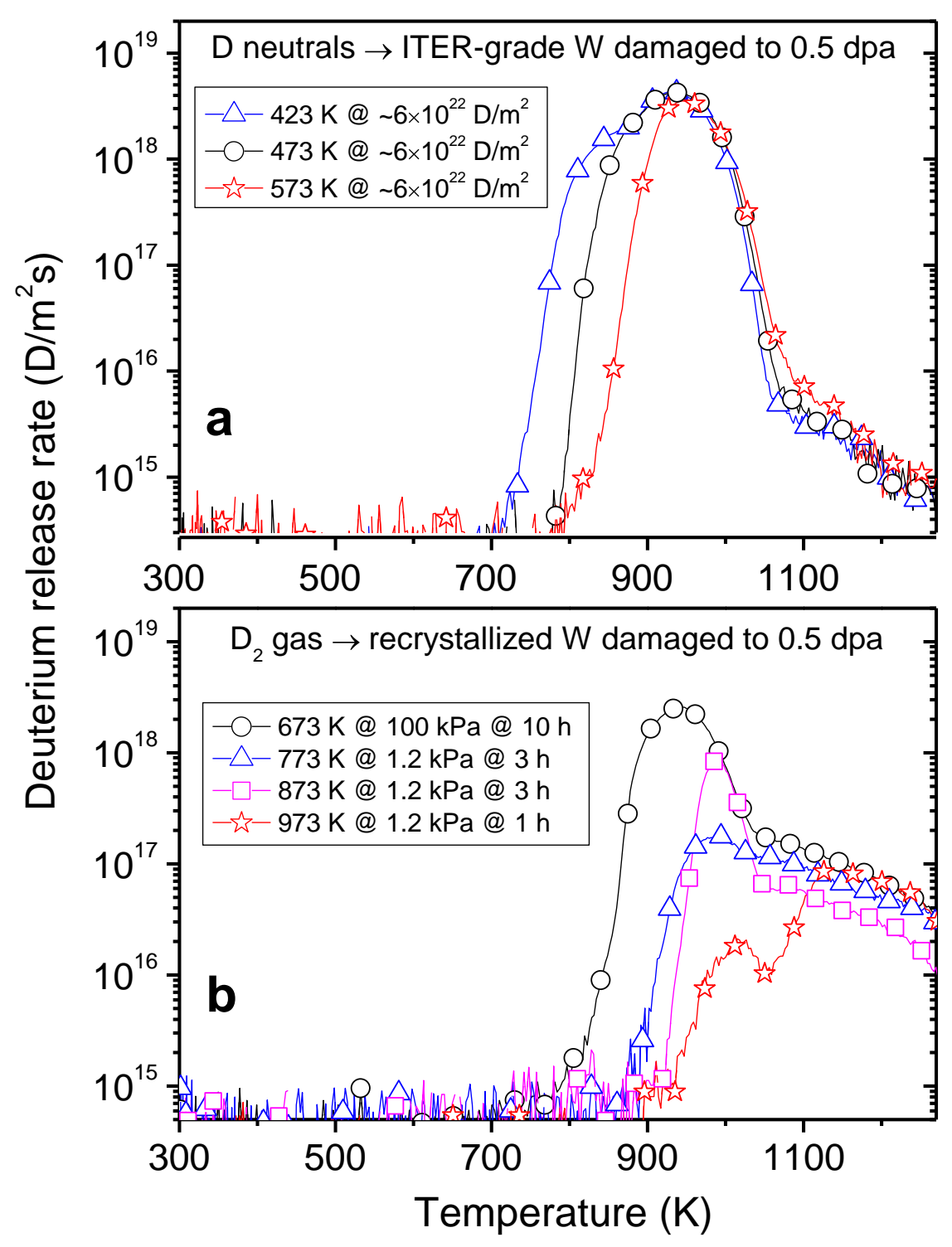

Figure 4. Thermal desorption spectra of $\mathrm{D}_{2}$ molecules for damaged ITER-grade $\mathrm{W}$ exposed to $\mathrm{D}$ neutrals (a) and recrystallized $\mathrm{W}$ exposed to $\mathrm{D}_{2}$ gas (b). Exposure temperatures, D implantation fluences, gas pressures and exposure durations are indicated in the legends. The TDS heating rate was $0.5 \mathrm{~K} / \mathrm{s}$. In both panels, the deuterium release rate is shown on a logarithmic scale. 